\title{
Transtornos mentais comuns em médicos e seu cotidiano de trabalho
}

\author{
Common mental disorders among physicians and their everyday practice \\ Maria Cristina F. de Lima Cabana', Ana Bernarda Ludermir², Érika R. Silva, Maria Luiza L. Ferreira4, Maria Emília R. Pinto ${ }^{5}$
}

\section{RESUMO}

Objetivo: Comparar o cotidiano de trabalho e a prevalência dos transtornos mentais comuns (TMC) dos médicos que exerciam suas atividades profissionais no serviço de emergência com os da UTI e enfermarias de um hospital geral da rede estadual em Recife, em 2004. Métodos: Estudo de prevalência tendo utilizado como instrumentos um questionário sobre o Cotidiano de Trabalho Médico e o Self Reporting Questionnaire (SRQ-20), para identificar os TMC. Foram descritas características demográficas, socioeconômicas e do cotidiano de trabalho dos médicos do hospital. Calculou-se a prevalência global dos TMC e por setor de trabalho. Resultados: Comparando os médicos da emergência com os da UTI e enfermarias, aqueles tinham vínculo empregatício com o Estado ( $p<0,0001)$, múltiplos empregos ( $p=0,004)$, maior carga horária semanal de trabalho ( $\geq 71$ horas) $(p=0,007)$, maior sensação de sobrecarga de trabalho $(95,74 \%, p=0,015)$ e recebiam no hospital até 5 salários mínimos ( $p<0,0001)$. Embora a diferença não tenha sido estatisticamente significante, a prevalência de TMC foi maior nos médicos da emergência (32,00\%), comparando-se aos da UTI (17,65\%) e enfermarias (17,54\%). Conclusão: Identificou-se a emergência como setor de maior prevalência de TMC e com médicos vivenciando piores condições de trabalho.

\begin{abstract}
Objective: To compare the day-to-day workload and prevalence of common mental disorders (CMD) among physicians that exercise their professional activities in the emergency service with those of the ICU and infirmaries of a state-run general emergency hospital in the city of Recife in 2004. Methods: Cross-sectional study which used a questionnaire elaborated to obtain information on the Physician's Day-to-day Workload and the Self Reporting Questionnaire (SRQ-20), to identify CMD. Demographic, socio-economic and day-to-day workload characteristics of the physicians of the hospital were described. The global prevalence of CMD and stratified by working sector was calculated. Results: Comparing the physicians of the emergency service with
\end{abstract}

1 Psicóloga clínica-hospitalar do Hospital Getúlio Vargas, da Secretaria Estadual de Saúde do Estado de Pernambuco, professora da graduação em Psicologia da Faculdade de Ciências Humanas ESUDA (PE), e Mestra em Saúde Coletiva.

2 Médica e Ph.D. em Epidemiologia, professora adjunta do Departamento de Medicina Social do Centro de Ciências da Saúde da Universidade Federal de Pernambuco (UFPE).

3 Auxiliar de pesquisa, bolsista de iniciação científica e graduanda de Psicologia na UFPE.

Recebido

13/03/2007

4 Bolsista de iniciação científica e graduanda de Medicina da Universidade de Pernambuco (UPE).

5 Voluntária e graduanda de Psicologia da Faculdade de Ciências Humanas ESUDA (PE). 


\section{Key-words}

Common mental disorders, physicians, working conditions. those of the ICU and infirmaries, the formers worked for the state $(p<0.0001)$, had multiple jobs $(p=0.004)$, had a greater weekly workload ( $\geq 71$ hours) $(p=0.007)$, presented a greater sensation of being overworked $(95.74 \%, p=0.015)$ and received up to 5 times the minimum salary at the hospital $(p<0.0001)$. Although the difference was not statistically significant, the prevalence of CMD was higher among those physicians in the emergency service (32.00\%) in comparison to those of the ICU (17.65\%) and the infirmaries (17.54\%). Conclusion: The emergency service was identified as the sector with the highest prevalence of CMD and with physicians experiencing the worst day-to-day working conditions.

\section{INTRODUÇÃO}

A passagem da medicina liberal para a tecnológica no Brasil mudou a relação do médico com seu trabalho e seu paciente. A relação médico-paciente passou a ser intermediada pelo Estado, pelas empresas médicas e de seguro-saúde e os médicos perderam a liberdade de decidir sua jornada de trabalho, o número de pacientes, o tempo disponível para cada um deles e de fixar sua remuneração. Foram separados de seus materiais de trabalho, perdendo a posse dos instrumentos para a instituição que organiza seu trabalho (Schraiber, 1993).

Pesquisa recente realizada pelo Sindicato dos Médicos de Pernambuco (2001) aponta que, apesar de, em média, os médicos pernambucanos possuírem dois empregos, 35,0\% têm três empregos ou mais. Os múltiplos vínculos de trabalho e a conseqüente longa jornada servem como uma compensação aos baixos salários, sobretudo na rede pública de saúde, sendo motivo de insatisfação da categoria. Gaspar et al. (1998) afirmam que boa parte dos médicos plantonistas chega a trabalhar mais de 36 horas seguidas, quase sem dormir, alertando que jornadas prolongadas de plantões noturnos levariam, inclusive, a freqüentes queixas de alterações de estados de humor, com significativos prejuízos à vida pessoal e à profissional.

As condições de trabalho médico, como privação do sono e sobrecarga de trabalho, além do estresse de lidar com doença, dor e morte cotidianamente, têm sido apontadas como fator de risco para a saúde mental deles (Nogueira-Martins, 1991; Kovács, 1992; Meleiro, 1998). Os médicos trabalham 15 horas por semana a mais que outros profissionais, maior número de anos e tiram menos férias (Nogueira-Martins, 2002). Nogueira-Martins (2002) descreveu a síndrome de burn out, caracterizada por sintomas somáticos, psicológicos e comportamentais conseqüentes ao estresse emocional crônico intermitente do médico, comprometendo, assim, sua qualidade de vida e atuação profissional. Estudos têm revelado altas taxas de suicídio entre médicos, superiores às de outras profissões (Meleiro, 1998). Para Noto (1984), o confronto diário com situações ansiogênicas no trabalho e a não-elaboração dos sentimentos vivenciados levariam os médicos a proteger-se por meio de mecanismos psíquicos de defesa que, freqüentemente, passam a fazer parte de sua personalidade. Tais vivências encontrariam expressão na impessoalidade e frieza afetiva no trato com os pacientes, na dissociação e projeção que permitem manter a morte e a doença só nos pacientes, na onipotência, na incapacidade de desempenhar outros papéis, na ausência de lazer e na restrição dos contatos sociais a apenas outros médicos, descritos pelo autor como uma "caracteropatia profissional".

Kovács (1992) afirmou que, dependendo da especialidade, o médico pode vivenciar sentimentos e expectativas diferentes, oscilando entre "tudo poder" - sentimento de onipotência - e a frustração de "nada poder" quando diante da morte - sentimento de impotência. Diante de situações de urgência, por exemplo, pouco se atenta para a demanda da equipe de saúde no que concerne à instrumentalização não só técnica e física, mas também psicológica para o exercício profissional em um cotidiano de dor e perdas (Sebastiani, 2002). Nessas situações, apesar de o paciente e sua família serem os pontos mais vulneráveis aos riscos e às ameaças da crise que vivenciam, a equipe de saúde também se expõe ao estresse, sobretudo em relação à intervenção técnica (Sebastiani, 2002).

Noto (1984) apontou o descuido e a desatenção das instituições formadoras para o que chama "toxicidade" elevada em termos psicológicos, tanto do curso quanto da profissão médica. O presente estudo teve como objetivo comparar o cotidiano de trabalho e a prevalência dos transtornos mentais comuns (TMC) dos médicos que exercem suas atividades profissionais no serviço de emergência com os da unidade de terapia intensiva (UTI) e enfermarias de um hospital geral de emergência da rede estadual, na cidade do Recife, em 2004.

\section{MÉTODOS}

\section{Área de estudo}

O presente estudo foi realizado numa unidade hospitalar de porte I (Hospital Geral de Urgência e Emergência), da rede pública de saúde do estado de Pernambuco, locali- 
zada no distrito sanitário IV, na cidade de Recife, com atendimentos ambulatorial e hospitalar, com um total de 478 leitos. A unidade hospitalar de estudo, aqui identificada como hospital A, oferece serviços em várias especialidades médicas, além de psicologia, fonoaudiologia, fisioterapia, nutrição, entre outros. Após a criação do Sistema Único de Saúde, está sob a gerência da Secretaria Estadual de Saúde de Pernambuco, atendendo pacientes de vários níveis socioeconômicos, predominando a população de baixa renda de todo o estado, além de estados vizinhos.

\section{População de estudo e coleta de dados}

Realizou-se um estudo transversal no período de agosto a dezembro de 2004. Todos os médicos do hospital A que atuavam na emergência, enfermarias e UTI, com vínculo empregatício permanente (Estado e Ministério da Saúde), foram incluídos no estudo. A coleta de dados só teve início após aprovação do projeto de pesquisa pelo Comitê de Ética em Pesquisa com seres humanos do Centro de Ciências da Saúde da UFPE (Ofício no 324/2004-CEP/CCS/UFPE), tendo ocorrido de acordo com os regimes (diarista e plantão) e turnos de trabalho da instituição. Para testar o instrumento e a receptividade dos médicos à pesquisa, realizou-se um estudo piloto com médicos da rede pública estadual, tendo-se, nessa oportunidade, treinado as auxiliares de pesquisa (duas bolsistas de iniciação científica e uma voluntária). Os questionários eram entregues num mesmo caderno, com o termo de consentimento livre e esclarecido, para que o médico conhecesse o teor da pesquisa. Quando devolvido às auxiliares de pesquisa, eram lacrados e colocados em bolsões plásticos para garantir o anonimato.

\section{Instrumentos de coleta de dados e elenco de variáveis}

Os dois questionários utilizados (Cotidiano de Trabalho Médico e SRQ-20) foram auto-aplicáveis. Foram também coletadas informações sobre sexo, idade, estado civil, número de filhos, rendas pessoal e domiciliar, além do número de pessoas que residiam com o médico e número de pessoas que dependiam economicamente dele, compondo a renda per capita domiciliar.

Quanto a características do cotidiano de trabalho médico, observaram-se tempo de serviço e vínculo empregatício no hospital A, tempo de formado, manutenção da escolha pela profissão médica, setor de trabalho no hospital A, especialidade (se clínico ou cirurgião) e tempo de serviço no setor de trabalho, jornada de trabalho total (incluindo o hospital A e todas as demais atividades profissionais/empregos), salário no hospital A e regime de trabalho (diarista ou plantonista, tanto no hospital A quanto em outros vínculos empregatícios públicos e/ou privados), acúmulo de atividades de plantão com atividade(s) diarista(s), sensação de sobrecarga de trabalho e o lidar no dia-a-dia com dor, morte e sofrimento.
Para identificar os TMC, utilizou-se o Self Reporting Questionnaire-20 (SRQ-20), desenvolvido por Harding et al. (1980) e validado no Brasil (Mari e Williams, 1986) com sensibilidade de $85 \%$ e especificidade de $80 \%$. É composto por 20 questões do tipo sim/não, 4 sobre sintomas físicos e 16 sobre distúrbios psicoemocionais. Com base no estudo de Pitta (2003) em trabalho de pesquisa com os profissionais de um hospital em São Paulo, o ponto de corte estabelecido para o presente estudo foi de oito e acima para os considerados suspeitos de TMC e de sete e abaixo para os considerados não suspeitos.

\section{Processamento e análise dos dados}

Os dados foram digitados duas vezes no programa EPI-INFO versão 6.0, por pessoas diferentes, e a análise estatística foi feita no programa Stata versão 6.0 para Windows. Realizouse a descrição das características demográficas, socioeconômicas e do cotidiano de trabalho dos médicos do hospital A, comparando-se os que trabalhavam na emergência com os da UTI e enfermaria. Calculou-se a prevalência global dos TMC e por setor de trabalho dos médicos. A significância estatística foi avaliada pelo teste do Qui-Quadrado de Pearson e Fisher (para pequenos valores) e o nível de significância estatística adotado foi de 0,05.

\section{RESULTADOS}

Dos 186 médicos do hospital A, 124 participaram do estudo, sendo 57 (45,97\%) da enfermaria, 50 (40,32\%) da emergência e $17(13,71 \%)$ da UTI. As perdas (57 médicos, representando $30,6 \%$ do universo estudado) se deram tanto por recusas $(16,1 \%)$ quanto pela impossibilidade de acesso aos médicos $(14,5 \%)$ motivada pela interdição de um dos blocos da instituição que necessitou de reformas em sua estrutura física. A taxa de resposta não variou com o setor, sendo de 70,27\% para a emergência, 77,27\% para a UTI e 66,67\% para as enfermarias $(p=0,61)$. Além disso, cinco $(2,7 \%)$ questionários que estavam com questões do SRQ-20 sem respostas não foram utilizados na presente análise.

Na análise de algumas características demográficas e socioeconômicas selecionadas para o estudo (Tabela 1), observouse que os médicos do hospital A eram, em sua maioria, do sexo masculino e casados. Enquanto $76,47 \%$ e $55,10 \%$ dos médicos da UTI e da emergência tinham entre 30 e 38 anos de idade, $52,63 \%$ dos médicos da enfermaria estavam com 47 anos ou mais de idade $(p<0,0001)$. A maioria dos médicos tinha até dois filhos, porém 37,50\% dos médicos da enfermaria tinham três ou mais filhos $(p=0,004)$. As diferenças de renda não foram estatisticamente significantes, no entanto, diferentemente dos médicos da UTI, grande parte dos que trabalhavam na enfermaria $(37,21 \%)$ e na emergência $(50,00 \%)$ apresentava renda per capita domiciliar igual a ou maior que 12 salários mínimos. 
Tabela 1. Características demográficas e socioeconômicas dos médicos distribuídos por setor de trabalho

\begin{tabular}{|c|c|c|c|c|c|c|c|}
\hline \multirow{4}{*}{$\begin{array}{l}\text { Características } \\
\text { demográficas e } \\
\text { socioeconômicas }\end{array}$} & \multicolumn{6}{|c|}{ Setor } & \multirow[t]{4}{*}{ Valor de $p$} \\
\hline & \multirow{2}{*}{\multicolumn{2}{|c|}{$\begin{array}{c}\text { Enfermaria } \\
n=57\end{array}$}} & \multirow{2}{*}{\multicolumn{2}{|c|}{$\begin{array}{c}\text { UTI } \\
n=17\end{array}$}} & \multirow{2}{*}{\multicolumn{2}{|c|}{$\begin{array}{l}\text { Emergência } \\
n=50\end{array}$}} & \\
\hline & & & & & & & \\
\hline & $\mathrm{n}$ & $\%$ & $n$ & $\%$ & $n$ & $\%$ & \\
\hline \multicolumn{8}{|l|}{ Sexo } \\
\hline Masculino & 37 & 64,91 & 09 & 52,94 & 34 & 68,00 & \multirow[t]{2}{*}{$p=0,521$} \\
\hline Feminino & 20 & 35,09 & 08 & 47,06 & 16 & 32,00 & \\
\hline \multicolumn{8}{|l|}{ Idade (em anos)* } \\
\hline $30 / 38$ & 12 & 21,05 & 13 & 76,47 & 27 & 55,10 & \multirow[t]{3}{*}{$p<0,0001$} \\
\hline $39 / 46$ & 15 & 26,32 & 02 & 11,76 & 13 & 26,53 & \\
\hline$\geq 47$ & 30 & 52,63 & 02 & 11,76 & 09 & 18,37 & \\
\hline \multicolumn{8}{|l|}{ Estado civil } \\
\hline Solteiro & 05 & 8,77 & 01 & 5,88 & 10 & 20,00 & \multirow[t]{3}{*}{$p=0,477$} \\
\hline Casado & 43 & 75,44 & 14 & 82,35 & 33 & 66,00 & \\
\hline Separado/viúvo & 09 & 15,79 & 02 & 11,76 & 07 & 14,00 & \\
\hline \multicolumn{8}{|l|}{ Número de filhos* } \\
\hline $0 / 1$ & 12 & 21,43 & 07 & 41,18 & 25 & 50,00 & \multirow[t]{3}{*}{$p=0,004$} \\
\hline 2 & 23 & 41,07 & 07 & 41,18 & 20 & 40,00 & \\
\hline$\geq 3$ & 21 & 37,50 & 03 & 17,65 & 05 & 10,00 & \\
\hline \multirow{2}{*}{\multicolumn{8}{|c|}{$\begin{array}{l}\text { Renda per capita } \\
\text { domiciliar** }\end{array}$}} \\
\hline & & & & & & & \multirow{4}{*}{$p=0,164$} \\
\hline Até 6,3 & 14 & 32,56 & 06 & 42,86 & 07 & 19,44 & \\
\hline 6,4 a 11,5 & 13 & 30,23 & 06 & 42,86 & 11 & 30,56 & \\
\hline$\geq 12$ & 16 & 37,21 & 02 & 14,29 & 18 & 50,00 & \\
\hline
\end{tabular}

*1 valor perdido; **31 valores perdidos.

Analisando-se as variáveis relacionadas ao cotidiano de trabalho médico no hospital A (Tabela 2) e em outros empregos mantidos pelo médico (Tabela 3), observou-se que os da emergência, considerando todos os aspectos, apresentavam um cotidiano com as piores condições de trabaIho ao se compararem, sobretudo, com os da enfermaria. Assim, 67,35\% trabalhavam na unidade havia no máximo 10 anos ( $p<0,0001$ ), 92,00\% tinham vínculo empregatício com a Secretaria de Saúde do Estado de Pernambuco $(p<0,0001)$ e 65,31\% recebiam no hospital onde se deu o estudo até 5 salários mínimos $(p<0,0001)$.

Tabela 2. Variáveis relacionadas ao cotidiano de trabalho médico no hospital A estratificadas por setor

\begin{tabular}{|c|c|c|c|c|c|c|c|}
\hline \multirow[t]{4}{*}{ Variáveis } & \multicolumn{6}{|c|}{ Setor } & \multirow[t]{4}{*}{ Valor de $p$} \\
\hline & \multirow{2}{*}{\multicolumn{2}{|c|}{$\begin{array}{c}\text { Enfermaria } \\
n=57\end{array}$}} & \multirow{2}{*}{\multicolumn{2}{|c|}{$\begin{array}{c}\text { UTI } \\
n=17\end{array}$}} & \multirow{2}{*}{\multicolumn{2}{|c|}{$\begin{array}{c}\text { Emergência } \\
n=50\end{array}$}} & \\
\hline & & & & & & & \\
\hline & $\mathrm{n}$ & $\%$ & $\mathrm{n}$ & $\%$ & $\mathrm{n}$ & $\%$ & \\
\hline \multicolumn{8}{|l|}{$\begin{array}{l}\text { Tempo no } \\
\text { hospital A } \\
\text { (em anos)* }\end{array}$} \\
\hline $1 / 10$ & 17 & 29,82 & 10 & 58,82 & 33 & 67,35 & $\mathrm{p}<0,0001$ \\
\hline$\geq 11$ & 40 & 70,18 & 07 & 41,18 & 16 & 32,65 & \\
\hline \multicolumn{8}{|l|}{$\begin{array}{l}\text { Vínculo } \\
\text { empregatício } \\
\text { no hospital A }\end{array}$} \\
\hline MS & 28 & 49,12 & 02 & 11,76 & 04 & 8,00 & $p<0,0001$ \\
\hline Estado & 29 & 50,88 & 15 & 88,24 & 46 & 92,00 & \\
\hline \multicolumn{8}{|c|}{$\begin{array}{l}\text { Tempo no } \\
\text { setor (em anos)* }\end{array}$} \\
\hline Até 5 & 15 & 26,79 & 02 & 11,76 & 17 & 34,00 & $p=0,120$ \\
\hline $6 / 10$ & 14 & 25,00 & 07 & 41,18 & 19 & 38,00 & \\
\hline$\geq 11$ & 27 & 48,21 & 08 & 47,06 & 14 & 28,00 & \\
\hline \multicolumn{8}{|l|}{$\begin{array}{l}\text { Salário no } \\
\text { hospital } A^{* *}\end{array}$} \\
\hline Até 5 & 21 & 41,18 & 13 & 76,47 & 32 & 65,31 & $\mathrm{p}<0,0001$ \\
\hline$>5$ até 10 & 12 & 23,53 & 03 & 17,65 & 15 & 30,61 & \\
\hline$>10$ & 18 & 35,29 & 01 & 5,88 & 02 & 4,08 & \\
\hline
\end{tabular}

Tabela 3. Variáveis relacionadas ao cotidiano de trabalho médico em outros empregos mantidos pelo médico estratificadas por setor do hospital A

\begin{tabular}{|c|c|c|c|c|c|c|c|}
\hline \multirow[t]{4}{*}{ Variáveis } & \multicolumn{6}{|c|}{ Setor } & \multirow[t]{4}{*}{ Valor de $p$} \\
\hline & \multirow{2}{*}{\multicolumn{2}{|c|}{$\begin{array}{c}\text { Enfermaria } \\
n=57\end{array}$}} & \multirow{2}{*}{\multicolumn{2}{|c|}{$\begin{array}{l}\text { UTI } \\
n=17\end{array}$}} & \multirow{2}{*}{\multicolumn{2}{|c|}{$\begin{array}{c}\text { Emergência } \\
\mathrm{n}=50\end{array}$}} & \\
\hline & & & & & & & \\
\hline & $\mathrm{n}$ & $\%$ & $\mathrm{n}$ & $\%$ & $\mathrm{n}$ & $\%$ & \\
\hline \multicolumn{8}{|l|}{$\begin{array}{l}\text { Tempo } \\
\text { de formado }\end{array}$} \\
\hline $6 / 10$ & 04 & 7,02 & 07 & 41,18 & 19 & 38,00 & $p<0,0001$ \\
\hline $11 / 20$ & 20 & 35,09 & 08 & 47,06 & 21 & 42,00 & \\
\hline$\geq 21$ & 33 & 57,89 & 02 & 11,76 & 10 & 20,00 & \\
\hline \multicolumn{8}{|c|}{$\begin{array}{l}\text { Manteria } \\
\text { escolha pela } \\
\text { profissão }\end{array}$} \\
\hline Sim & 47 & 82,46 & 13 & 76,47 & 31 & 62,00 & $p=0,055$ \\
\hline Não & 10 & 17,54 & 04 & 23,53 & 19 & 38,00 & \\
\hline \multicolumn{8}{|c|}{ № de empregos* } \\
\hline Até 2 & 17 & 30,36 & 02 & 11,76 & 03 & 6,00 & $p=0,004$ \\
\hline 3 a 4 & 31 & 55,36 & 08 & 47,06 & 35 & 70,00 & \\
\hline$>4$ & 08 & 14,29 & 07 & 41,18 & 12 & 24,00 & \\
\hline \multicolumn{8}{|c|}{$\begin{array}{l}\text { Carga horária } \\
\text { diária* }\end{array}$} \\
\hline $3 / 8$ & 15 & 26,32 & 01 & 5,88 & 05 & 10,20 & $p=0,119$ \\
\hline $9 / 12$ & 28 & 49,12 & 13 & 76,47 & 32 & 65,31 & \\
\hline$\geq 13$ & 14 & 24,56 & 03 & 17,65 & 12 & 24,49 & \\
\hline \multicolumn{8}{|c|}{$\begin{array}{l}\text { Carga horária } \\
\text { semanal* }\end{array}$} \\
\hline $15 / 59$ & 26 & 45,61 & 03 & 17,65 & 09 & 18,37 & $p=0,007$ \\
\hline $60 / 70$ & 19 & 33,33 & 08 & 47,06 & 16 & 32,65 & \\
\hline$\geq 71$ & 12 & 21,05 & 06 & 35,29 & 24 & 48,98 & \\
\hline \multicolumn{8}{|c|}{$\begin{array}{l}\text { Emenda plantão } \\
\text { com outro turno** }\end{array}$} \\
\hline Sim & 15 & 34,09 & 14 & 82,35 & 73 & 86,00 & $p<0,0001$ \\
\hline Não & 29 & 65,91 & 03 & 17,65 & 07 & 14,00 & \\
\hline \multicolumn{8}{|c|}{$\begin{array}{l}\text { Horas semanais } \\
\text { dedicadas ao } \\
\text { consultório }\end{array}$} \\
\hline $1 / 6$ & 10 & 22,73 & 08 & 80,00 & 12 & 41,38 & $p=0,002$ \\
\hline \multirow{2}{*}{\multicolumn{8}{|c|}{$\begin{array}{l}\text { Emprego } \\
\text { no sistema } \\
\text { hospitalar } \\
\text { privado }\end{array}$}} \\
\hline & & & & & & & \\
\hline $\begin{array}{l}\text { Sim } \\
\text { Não }\end{array}$ & $\begin{array}{l}49 \\
08\end{array}$ & $\begin{array}{l}85,96 \\
14,04\end{array}$ & $\begin{array}{l}15 \\
02\end{array}$ & $\begin{array}{l}88,24 \\
11,76\end{array}$ & $\begin{array}{l}41 \\
09 \\
\end{array}$ & $\begin{array}{l}82,00 \\
18,00\end{array}$ & $p=0,785$ \\
\hline
\end{tabular}

Comparando o cotidiano de trabalho dos outros empregos, os médicos da emergência diferenciam-se dos da enfermaria e assemelham-se aos da UTI em relação ao tempo de formado distribuído entre 6/10 anos e 11/20 anos (80\% da emergência e 88,24\% da UTI), número de empregos, mantendo entre três e mais empregos (94\% da emergência e 88,24\% da UTI) e emendam plantão com outro turno de trabalho ( $86 \%$ da emergência e 82,35\% da UTI). Apesar de a maioria da emergência afirmar que hoje ainda escolheria a mesma profissão (62,00\%), um percentual expressivo (38,00\%) atualmente não optaria pela medicina. Contabilizando todos os empregos, trabalhavam entre 9 e 12 horas $(65,31 \%)$ por dia e 71 ou mais horas semanais (48,98\%; $p=0,007)$ e 58,62\% dedicavam 7 ou mais horas semanais ao consultório e também trabalhavam no sistema hospitalar privado (82,00\%). No que diz respeito ao regime de trabalho, 98,00\% dos médicos da emergência do 
hospital A são plantonistas ou, ainda, acumulam plantão com outro turno na própria instituição, enquanto, na UTI, 29,51\% são diaristas (dados não apresentados em tabela).

Os médicos também foram questionados quanto à sensação de sobrecarga (Tabela 4) relacionada a seu trabalho, observando-se que a maioria se sentia sobrecarregada (76,60\% da enfermaria e $76,47 \%$ da UTI), sobretudo os que atuavam na emergência $(95,74 \% ; p=0,015)$. A maior parte dos médicos do hospital A alegou que a carga horária diária/semanal de trabalho (72,50\% dos médicos da enfermaria, 92,31\% da UTI e 87,23\% da emergência) era responsável pela sensação de sobrecarga. A privação de sono também foi apontada como causa de sensação de sobrecarga, principalmente pelos médicos que atuavam na emergência $(68,09 \% ; p=0,001)$.

Tabela 4. Variáveis relacionadas à sensação de sobrecarga em virtude do trabalho médico, estratificadas por setor

\begin{tabular}{|c|c|c|c|c|c|c|c|}
\hline \multirow[t]{4}{*}{ Variáveis } & \multicolumn{6}{|c|}{ Setor } & \multirow[t]{4}{*}{ Valor de $\mathrm{p}$} \\
\hline & \multirow{2}{*}{\multicolumn{2}{|c|}{$\begin{array}{c}\text { Enfermaria } \\
\mathrm{n}=57\end{array}$}} & \multirow{2}{*}{\multicolumn{2}{|c|}{$\begin{array}{c}\text { UTI } \\
n=17\end{array}$}} & \multirow{2}{*}{\multicolumn{2}{|c|}{$\begin{array}{c}\text { Emergência } \\
n=50\end{array}$}} & \\
\hline & & & & & & & \\
\hline & $\mathrm{n}$ & $\%$ & $\mathrm{n}$ & $\%$ & $\mathrm{n}$ & $\%$ & \\
\hline \multicolumn{8}{|c|}{$\begin{array}{l}\text { Sensação de } \\
\text { sobrecarga com } \\
\text { o trabalho }\end{array}$} \\
\hline Sim & 36 & 76,60 & 13 & 76,47 & 45 & 95,74 & $p=0,015$ \\
\hline Não & 11 & 23,40 & 04 & 23,53 & 02 & 4,26 & \\
\hline \multicolumn{8}{|c|}{ Fatores apontados como sobrecarga de trabalho } \\
\hline \multicolumn{8}{|c|}{$\begin{array}{l}\text { Carga horária } \\
\text { diária/semanal } \\
\text { de trabalho }\end{array}$} \\
\hline Sim & 29 & 72,50 & 12 & 92,31 & 41 & 87,23 & $p=0,151$ \\
\hline Não & 11 & 27,50 & 01 & 7,69 & 06 & 12,77 & \\
\hline \multicolumn{8}{|l|}{$\begin{array}{l}\text { Privação } \\
\text { de sono }\end{array}$} \\
\hline Sim & 12 & 30,00 & 06 & 46,15 & 32 & 68,09 & $p=0,001$ \\
\hline Não & 28 & 70,00 & 07 & 53,85 & 15 & 31,91 & \\
\hline
\end{tabular}

Não se observaram diferenças estatisticamente significantes entre os médicos dos diversos setores quanto ao lidarem no cotidiano de trabalho com dor, morte e sofrimento (Tabela 5), ressaltando-se que 54\% dos médicos do setor de emergência do hospital A afirmaram que seu trabalho Ihes causava sofrimento. Porém, observou-se que a maioria dos médicos de todos os setores assumiu que era sofrido lidar com algumas de suas atribuições (queixas de dor e sofrimento de seus pacientes, comunicar ao seu paciente diagnóstico de doença grave ou fora de possibilidades terapêuticas e lidar com a morte no trabalho).

A prevalência global de TMC na população estudada foi de $23,39 \%$ e sua análise por setor de trabalho no hospital A mostrou que a UTI (17,65\%) e a enfermaria (17,54\%) apresentaram praticamente a mesma taxa. Os médicos da emergência apresentaram uma taxa (32,00\%) que representa quase o dobro de TMC ao comparar-se com os demais setores, não se encontrando, no entanto, diferença estatisticamente significante $(p=0,216)$.
Tabela 5. Variáveis relacionadas ao lidar no cotidiano de trabalho com dor, morte e sofrimento estratificadas por setor

\begin{tabular}{|c|c|c|c|c|c|c|c|}
\hline \multirow[t]{4}{*}{ Variáveis } & \multicolumn{6}{|c|}{ Setor } & \multirow[t]{4}{*}{ Valor de $p$} \\
\hline & \multirow{2}{*}{\multicolumn{2}{|c|}{$\begin{array}{c}\text { Enfermaria } \\
n=57 \\
\end{array}$}} & \multirow{2}{*}{\multicolumn{2}{|c|}{$\begin{array}{c}\text { UTI } \\
n=17\end{array}$}} & \multirow{2}{*}{\multicolumn{2}{|c|}{$\begin{array}{c}\text { Emergência } \\
n=50\end{array}$}} & \\
\hline & & & & & & & \\
\hline & $n$ & $\%$ & $n$ & $\%$ & $n$ & $\%$ & \\
\hline \multicolumn{8}{|l|}{$\begin{array}{l}\text { Sofrimento } \\
\text { com } 0 \\
\text { trabalho* }\end{array}$} \\
\hline $\begin{array}{l}\text { Sim } \\
\text { Não }\end{array}$ & $\begin{array}{l}26 \\
29\end{array}$ & $\begin{array}{l}47,27 \\
52,73\end{array}$ & $\begin{array}{l}06 \\
11\end{array}$ & $\begin{array}{l}35,29 \\
64,71\end{array}$ & $\begin{array}{l}27 \\
23\end{array}$ & $\begin{array}{l}54,00 \\
46,00\end{array}$ & $p=0,407$ \\
\hline \multicolumn{8}{|c|}{$\begin{array}{l}\text { Sofrimento } \\
\text { ao lidar com } \\
\text { queixas de } \\
\text { dor e } \\
\text { sofrimento } \\
\text { dos pacientes* }\end{array}$} \\
\hline $\begin{array}{l}\text { Sim } \\
\text { Não }\end{array}$ & $\begin{array}{l}42 \\
15\end{array}$ & $\begin{array}{l}73,68 \\
26,32\end{array}$ & $\begin{array}{l}10 \\
06\end{array}$ & $\begin{array}{l}62,50 \\
37,50\end{array}$ & $\begin{array}{l}35 \\
14\end{array}$ & $\begin{array}{l}71,43 \\
28,57\end{array}$ & $p=0,675$ \\
\hline \multicolumn{8}{|c|}{$\begin{array}{l}\text { Sofrimento } \\
\text { ao comunicar } \\
\text { diagnóstico } \\
\text { de doença } \\
\text { grave*** }^{* *}\end{array}$} \\
\hline $\begin{array}{l}\text { Sim } \\
\text { Não }\end{array}$ & $\begin{array}{l}50 \\
07\end{array}$ & $\begin{array}{l}87,72 \\
12,28\end{array}$ & $\begin{array}{l}12 \\
05\end{array}$ & $\begin{array}{l}70,59 \\
29,41\end{array}$ & $\begin{array}{l}37 \\
12\end{array}$ & $\begin{array}{l}75,51 \\
24,49\end{array}$ & $p=0,125$ \\
\hline \multicolumn{8}{|l|}{$\begin{array}{l}\text { Sofrimento } \\
\text { ao lidar com } \\
\text { a morte no } \\
\text { trabalho*** }\end{array}$} \\
\hline $\begin{array}{l}\text { Sim } \\
\text { Não }\end{array}$ & $\begin{array}{l}47 \\
09\end{array}$ & $\begin{array}{l}83,93 \\
16,07\end{array}$ & $\begin{array}{l}11 \\
06\end{array}$ & $\begin{array}{l}64,71 \\
35,29 \\
\end{array}$ & $\begin{array}{l}35 \\
13 \\
\end{array}$ & $\begin{array}{l}72,92 \\
27,08 \\
\end{array}$ & $p=0,163$ \\
\hline
\end{tabular}

*2 valores perdidos, ${ }^{* * 1}$ valor perdido; ${ }^{* * * 3}$ valores perdidos.

\section{DISCUSSÃO}

A presente pesquisa identificou a emergência como setor não só com maior prevalência de TMC (32\%), comparando-se à UTI e à enfermaria do hospital A, mas também com médicos vivenciando as piores condições de trabalho. No entanto, o acaso e a existência de vieses poderiam desqualificar as diferenças encontradas nesta investigação. Em primeiro lugar, pontua-se que a associação entre os TMC e o trabalho na emergência pode ter sido aqui atenuada pelo erro tipo II, ou seja, a quantidade de médicos recrutados pelo estudo não foi suficiente para detectar uma diferença estatisticamente significante, mesmo que esta exista (Hennekens, 1987).

Tentou-se minimizar o viés de seleção trabalhando-se com a totalidade dos médicos, bem como solicitando permissão das chefias para abordá-los, buscando maior participação na pesquisa. Ao comparar características como sexo e vínculo empregatício com o hospital A entre participantes e não-participantes do estudo, verificou-se que, quanto ao sexo, a diferença encontrada entre os grupos não foi estatisticamente significante $(p=0,183)$. No entanto, a diferença entre os participantes e não-participantes foi estatisticamente significante $(p=0,049)$ quanto ao vínculo empregatício, embora a maioria de ambos os grupos fosse formada por funcionários do Estado. 
Procurou-se minimizar o viés de informação, sobretudo quanto ao salário no hospital $\mathrm{A}$, renda per capita e respostas ao próprio SRQ-20, com o anonimato das respostas e a utilização de questionários auto-aplicáveis. Quanto a erros na classificação dos TMC, buscou-se um instrumento já validado no Brasil (Mari e Williams, 1986), escolhendo um ponto de corte baseado em estudo anterior com profissionais de saúde (Pitta, 2003). Sabe-se, porém, que a avaliação da saúde mental pode ter sido influenciada pelo momento de vida e trabalho de cada médico. Da mesma forma, os TMC podem não ter sido detectados nos médicos já em tratamento médico/psicológico.

É interessante ressaltar a dificuldade de acesso e aceitação da categoria médica enquanto alvo de estudo, o que pode ser observado na fala de alguns deles: "Essa pergunta do salário é complicada mesmo!". "Esse questionário que vocês deram pra responder é pra deixar todo mundo depressivo. Pergunta se a gente dorme bem, se sente cansaço..." "Ainda estou pensando se vou responder, se decidir eu entrego... Passe aqui no ambulatório..." (sic).

A prevalência global dos TMC na população estudada foi de $23,39 \%$, apresentando-se um pouco mais elevada ao comparar-se com outros estudos na realidade brasileira, tanto com médicos (19,20\%), no estudo de Rego (1992), quanto com variados profissionais de saúde (20,80\%), em Pitta (2003).

A maior concentração de jovens na emergência do hospital A pode-se justificar pelo fato de os serviços de emergência do Estado representarem, geralmente, a porta de entrada para médicos concursados no serviço público de saúde.

O presente estudo identificou uma predominância de médicos casados para todos os setores observados e renda entre 10 e 20 salários mínimos para os da emergência, concordando com dados do perfil do médico pernambucano (Simepe, 2001).

Quanto ao cotidiano de trabalho médico no hospital A, observando tempos de serviço, na profissão e no setor, uma primeira constatação é que quanto maior o tempo de serviço nesse hospital ( $\geq 11$ anos), menor o número de médicos que trabalham na emergência (16 médicos; 32,00\%). O caminho contrário foi observado para a enfermaria, ou seja, 70,18\% dos médicos desse setor estão no hospital A há 11 ou mais anos. Observa-se que o tempo de permanência no mesmo setor de trabalho difere entre os setores, tendo-se identificado que na emergência há uma importante concentração de médicos (34,00\%) que estavam havia menos tempo no setor (até 5 anos). 0 mesmo raciocínio pode ser tomado para o tempo de formado, observando-se que quanto mais tempo na profissão, mais o médico foi encontrado nas enfermarias e menos na emergência (Tabela 2). Esses achados apontam a emergência como o setor com maior exposição ao sofrimento e evitado pelos médicos, sobretudo os mais antigos na instituição.
Quanto ao número de empregos mantidos pelo médico, na presente pesquisa, a maioria dos médicos da enfermaria (55,36\%), UTI (47,06\%) e emergência (70,00\%) mantinha entre três e quatro empregos, encontrando-se, desta forma, um maior número de empregos mantidos pelo médico que o encontrado pelas pesquisas de Machado (1997) e do Sindicato dos Médicos de Pernambuco (2001). Atentando-se para os dados referidos, observa-se que com o decorrer dos anos (1997, 2001 e 2004), um maior número de empregos é mantido pelo médico como provável forma de compensação pelos baixos salários recebidos pela categoria.

Múltiplos empregos trazem em conseqüência uma longa jornada semanal de trabalho. A maioria dos médicos da emergência $(48,98 \%)$ trabalha entre 71 ou mais horas semanais e, provavelmente, mais dias por semana que os demais médicos, incluindo finais de semana e feriados. Eles superam, assim, a carga horária semanal da maioria dos médicos dos outros setores, sendo seguidos mais de perto apenas pelos da UTI que referiram, em sua maioria, trabalhar entre 60 e 70 horas (47,06\%) semanais. Baixos salários no hospital A versus mais altas rendas per capita remetem mais uma vez ao estudo do perfil do médico de Pernambuco (2001) que observou que os múltiplos vínculos de trabalho e conseqüente longa jornada serviam como compensação aos baixos salários, sobretudo na rede pública de saúde, sendo motivo de insatisfação da categoria. A esse respeito, vários estudos apontam para a relação entre maior número de empregos, extensão da carga horária de trabalho como compensação aos baixos salários e desgaste associado ao trabalho médico (Rego, 1992; Machado, 1997; Arenas-Monreal et al., 2004; Feliciano et al., 2005).

A sensação de sobrecarga com o trabalho médico, por sua vez, foi referida por expressivo percentual dos médicos do hospital A, encontrando-se na emergência quase maioria absoluta de respostas positivas (95,74\%). A carga horária diária/semanal de trabalho e a privação de sono foram apontadas como maiores motivos para a sensação de sobrecarga, sobretudo para os médicos da emergência.

Os médicos da emergência do hospital A emendam plantão com outro turno de trabalho $(86,00 \%)$, como também a maioria da UTI (82,35\%) (Tabela 2). Grande percentual dos médicos da emergência trabalha ainda no consultório e no sistema hospitalar privado. Além do desgaste do plantão, observa-se que os médicos da emergência ainda precisam lidar com grande diversificação de atividades profissionais, que requer perfil e formas de atuações distintos, exigindo do profissional adaptação a cada especificidade de trabalho.

Ressalta-se que, nesse setor, encontrou-se expressivo percentual dos que, atualmente, não escolheriam a profissão médica (38,00\%). É, sobretudo, na emergência pública, seja pelo grande volume de pacientes, seja pelo reduzido poder de resolutividade do médico diante dos grandes li- 
mites do serviço para atender a tal demanda, que o estresse se faz presente. Somam-se o ritmo intenso e acelerado de trabalho, o acúmulo de pacientes sem definição terapêutica, pela lentidão nos encaminhamentos dos casos, que necessitam desde um exame até um leito na UTI, e a impotência do profissional. Assim, destaca-se que houve médicos que receberam bem a pesquisa, pontuando a necessidade desse tipo de estudo, mostrando satisfação em ter espaço para expressar e dar voz à sua opinião: "Me interessei muito nessa pesquisa, ela será publicada?". "O questionário é grande, mas é uma pesquisa muito boa..." "Os médicos estão doentes! Essa pesquisa será uma bomba!" "Respondi o questionário com vontade!" (sic).

Um estudo publicado em 2005 (Feliciano et al., 2005), conduzido em cinco emergências pediátricas públicas do Recife, espelha bem o que anteriormente se descreveu. As autoras fazem reflexões em torno da síndrome de burn out (que se refere a estresse associado ao trabalho), identificando a percepção dos profissionais de saúde quanto ao desgaste emocional, encontrando conflitos entre o volume de trabalho e a exigência de qualidade do serviço prestado, o lidar com situações de risco de morte de seus pacientes, necessidade de múltiplos empregos pelos baixos salários, falta de suporte institucional impedindo maior autonomia e controle sobre o trabalho e reconhecimento de sofrimento e adoecimento de membros da equipe como algo comum. Outro aspecto observado foram as atitudes diante do trabaIho percebendo que os profissionais desenvolvem relações afetivas com aqueles que cuidam, exacerbando ansiedades, ou racionalização expressa pelo distanciamento emocional dos pacientes.

O presente estudo também identificou que a maior parte dos médicos da emergência (54,00\%) assume que seu trabalho Ihe causa sofrimento, e mesmo quando a maioria dos que trabalham na enfermaria (52,73\%) e UTI (64,71\%) afirma que seu trabalho não Ihe causa sofrimento, se contradiz ao afirmar ser sofrido lidar com queixas de dor e sofrimento de seus pacientes (73,68\% da enfermaria, $62,50 \%$ da UTI e 71,43\% da emergência). Também aponta ser sofrido comunicar ao paciente diagnóstico de doença grave/fora de possibilidades terapêuticas (enfermaria, 87,72\%, UTI, 70,59\% e enfermaria, 75,51\%), bem como o lidar com a morte no seu trabalho (enfermaria, 83,93\%, UTI, 64,71\% e emergência, 72,92\%).

Estudos apontam o quanto o lidar com dor e morte no cotidiano pode ser sofrido, levando o médico a confrontarse com a própria morte e com sentimentos de impotência, expressos em grande desgaste emocional, interferindo mesmo na relação médico-paciente (Kovács, 1992; Michelini, 2001). Quintana et al. (2002) propuseram melhor preparo do médico, em sua formação, para lidar com a morte, afir- mando que estes se utilizam de mecanismo de negação para se defender da angústia gerada pela morte de um paciente, por vezes até resistindo a informar a seu paciente o seu diagnóstico.

Nogueira-Martins (1991 e 2002) fala de "poderosas radiações psicológicas" ao referir-se ao contato íntimo com o adoecer no exercício profissional, enfatizando o caráter estressante da tarefa médica, em especial nas emergências públicas, sendo intensificada pelo volume de pacientes e precárias condições de trabalho, levando, inclusive, a reações hostis de pacientes e familiares. Ressalta que a assistência médica nos serviços de emergência pública expõe o médico a tão dramáticas situações talvez jamais vividas em outras atividades profissionais, em tempos de paz. Nos dois hospitais observados por Deslandes (2002), os profissionais emprestavam nomes como "Bósnia" e "Vietnã" a alguns espaços, dentro de seus ambientes de trabalho, sendo bastante sugestivos do "front de guerra" que enfrentam todos os dias em seu cotidiano nas emergências públicas. Sobrecarga de trabalho, sensação de desprestígio e falta de reconhecimento pelo Estado e pela própria população, verse tendo que "escolher" que paciente grave precisa receber cuidados, estresse de ter que dar conta da desorganização do serviço e da rede de saúde, pressão sofrida e falta de condições técnicas no seu trabalho são referidos como desencadeadoras de sofrimento nos profissionais.

Estudos (Nogueira-Martins, 1991; Deslandes, 2002; Pitta, 2003) têm descrito o risco à saúde mental advindo da atividade de profissionais de saúde, inclusive da categoria médica, uma vez que os expõem a um cotidiano de sofrimento no contato com os pacientes e seus familiares. A presente investigação oferece um olhar epidemiológico sobre a saúde mental do médico de um hospital público de emergência, contribuindo, desta forma, tanto para caracterizar o perfil dessa categoria profissional na unidade hospitalar A quanto para suscitar reflexões sobre as condições de trabalho a que está submetida não só esta categoria profissional, mas todos os demais expostos, sobretudo, ao setor de emergência.

\section{CONCLUSÃO}

O presente estudo identificou a emergência como o setor de maior prevalência de TMC e com médicos vivenciando piores condições de trabalho.

Agradecimentos: $\mathrm{O}$ trabalho de campo foi financiado pela Fundação de Amparo à Ciência e Tecnologia do Estado de Pernambuco (Facepe). 


\section{REFERÊNCIAS}

Arenas-Monreal L et al. Las instituciones de Salud y el autocuidado de los médicos. Salud Publica México. Cuernavaca, 46, 4: 326-32, 2004.

Deslandes SF. Frágeis deuses: profissionais da emergência entre os danos da violência e a recriação da vida. Rio de Janeiro: Fiocruz; 2002.

Feliciano KVO, Kovacs MH, Sarinho SW. Sentimentos de profissionais dos serviços de pronto-socorro pediátrico: reflexões sobre o burn out. Rev Bras Saúde Mater Infant, 5 (3): 319-28, 2005.

Gaspar S, Moreno C, Menna-Barreto L. Os plantões médicos, o sono e a ritmicidade biológica. Rev Assoc Méd Bras, 44 (3): 239-45, 1998.

Harding TW, Arango MV, Baltazar J, Climent CE, Ibrahim HHA, Ladrido-Ignacio L et al. Mental disorders in primary health care: a study of the frequency and diagnosis in four developing countries. Psychol Med, 10: 231-42, 1980.

Hennekens CH, Buring JE. Epidemiology in medicine. Boston: Little, Brown and Company; 1987.

Kovács MJ. Profissionais de saúde diante da morte. In: Morte e desenvolvimento humano. Casa do Psicólogo, p. 226-43, São Paulo, 1992.

Machado MH (coord). Os médicos no Brasil: um retrato da realidade. Rio de Janeiro: Fiocruz; 1997.

Mari JJ, Williams PAA. Validity study of a psychiatric screening questionnaire (SRQ 20) in primary care in city of São Paulo. Br J Psychiatry, 148: 23-6, 1986.
Meleiro AMA. Suicídio entre médicos e estudantes de medicina. Rev Assoc Méd Bras, 2 (44): 135-40, 1998

Michelini C. Atenção para os médicos e cuidadores. Viver Psicologia, 98: 16-7, 2001.

Nogueira-Martins LA. Atividade médica: fatores de risco para a saúde mental do médico. Rev Bras Clín Ter, 20 (9): 355-64, 1991.

Nogueira-Martins LA. Saúde Mental dos Profissionais de Saúde. Psychiatry on-line Brazil (7), abril, 2002. Disponível em <http://www.polbr.med.br /arquivo/artig00402-a.htm>. Acesso em 09/12/2004.

Noto JRS. A emergência de caracteropatia profissional em estudantes do quinto ano médico. Bol Psiquiatr, 17 (3): 101-7, 1984

Pitta A. Hospital: dor e morte como ofício. 5a edição. São Paulo: Annablume/ Hucitec; 2003.

Quintana AM, Cecim OS, Henn CG. 0 preparo para lidar com a morte na formação do profissional de medicina. Rev Bras Educ Méd, 26 (3): 204-10, 2002.

Rego MPCMA. Trabalho Hospitalar e Saúde Mental. 0 Caso de um Hospital Geral e Público no Município do Rio de Janeiro. Dissertação de Mestrado. Rio de Janeiro: UERJ/IMS,1992.

Schraiber LB. 0 Médico e seu Trabalho: Limites da Liberdade. São Paulo: Hucitec; 1993.

Sebastiani RW. A equipe de saúde frente às situações de crise e emergência no hospital geral: aspectos psicológicos. In: Camon VAA (org.). Urgências psicológicas no hospital. Pioneira Thomson, p. 31-9, São Paulo, 2002.

Simepe. Perfil do Médico Pernambucano (CD-ROM). Pesquisa de Opinião. Recife: Datamétrica; 2001. 